\title{
Necrose epidérmica metabólica em cães
}

\author{
Metabolic epidermal necrosis in dogs \\ Lissandro Gonçalves Conceição ${ }^{I^{*}}$ Lívia Maria Rosa Acha ${ }^{\mathrm{I}}$ \\ Fabrícia Hallack Loures ${ }^{I}$ José do Carmo Lopes Moreira ${ }^{\mathrm{I}}$
}

\begin{abstract}
A necrose epidérmica metabólica é uma rara enfermidade endócrino-metabólica, com importantes manifestações cutâneas, possuindo paralelo clinicopatológico com o eritema necrolítico migratório em humanos. O presente estudo tem por objetivo relatar três casos clínicos de NEM em cães acometidos por dermatite eritematosa, crostosa e ulcerativa associada à hepatopatia. O diagnóstico definitivo foi alcançado a partir do exame dermatopatológico. O prognóstico é desfavorável e os três animais morreram, apesar do tratamento.
\end{abstract}

Palavras-chave: necrose epidérmica metabólica, eritema necrolítico migratório, cão, hepatopatia.

\section{ABSTRACT}

Metabolic epidermal necrosis is a rare endocrine metabolic disease, characterized by dermatological signs which has clinical and pathological similarity with necrolytic migratory erythema in humans. The present report describes three cases of MEN in dogs affected with erythematous ulcerative crusting dermatitis associated with hepatopathy. The diagnosis was based on cutaneous histopathology. The prognosis is poor and the three dogs died despite the treatment.

Key words: necrolytic migratory erythema, metabolic epidermal necrosis, dog, hepatopathy.

A necrose epidérmica metabólica (NEM) é uma rara desordem endócrino-metabólica, que se manifesta por sinais cutâneos e sistêmicos. Primeiramente descrita em humanos e associada à neoplasma pancreático secretor de glucagon, a NEM também é relatada em cães e está comumente associada à doença hepática (BYRNE, 1999; MILLER et al.,1990; OUTERBRIDGE, 2005; PATEL et al., 1996; SCOTT et al., 2001). O eritema necrolítico migratório (ENM) descrito em humanos possui paralelo clínico e histológico com a NEM em cães. O ENM é característico da síndrome glucagonoma, sendo observado em pacientes com neoplasmas pancreáticos secretores de glucagon ou, mais raramente, com cirrose hepática e outras doenças gastrintestinais (BYRNE, 1999; PUJOL et al., 2004). Poucos relatos nacionais existem dessa enfermidade em cães na literatura indexada. O objetivo deste trabalho é descrever alterações clinicopatológicas em três cães acometidos por essa enfermidade.

Caso 1: Cão adulto, macho, sem raça definida, foi atendido com queixa de lesões de pele e coxins, dificuldade de caminhar, letargia, sialorréia, secreção nasal serosa, fezes amolecidas e urina de coloração escura. Ao exame físico, constatou-se emaciação, odor fétido, pelagem sem brilho e quebradiça com placas eritematosas, descamativas e crostosas, sobretudo nos pontos de apoio, como cotovelos e jarretes, hiperceratose e fissuras em todos os coxins (Figura 1A), eritema, edema e exsudação em junções mucocutâneas e escroto, placas eritematosas e exsudativas encimadas por crostas melicéricas no abdome ventral e descamação nas pinas. O cão apresentava também aumento de linfonodos préescapulares e mucosas pouco coradas. O hemograma

IDepartamento de Veterinária, Universidade Federal de Viçosa (UFV), Serviço de Dermatopatologia Comparada. Av. PH Rolphs, s/ n, Centro, 36570-000 Viçosa, MG, Brasil. E-mail: lissandro@ufv.br. *Autor para correspondência. 

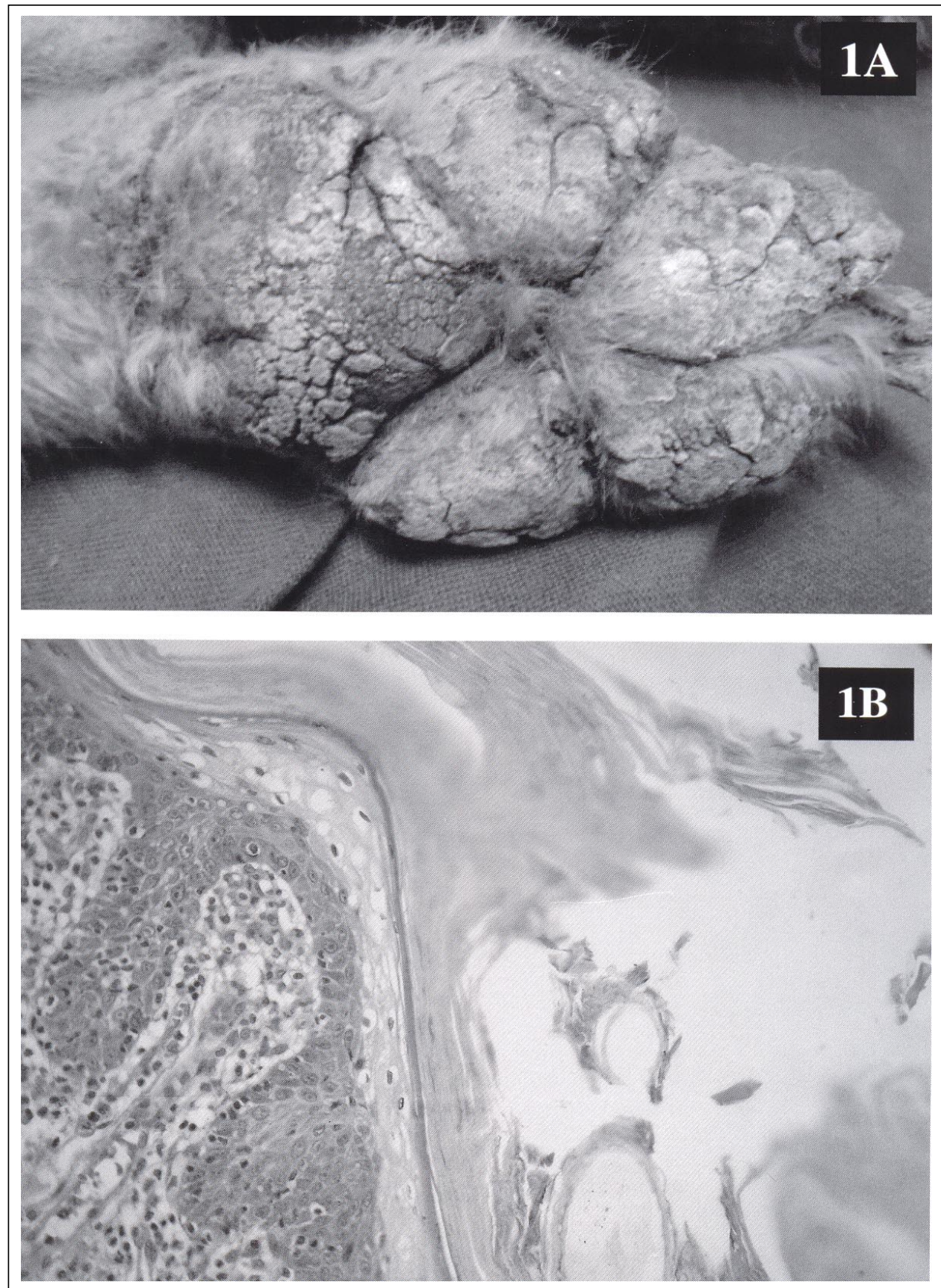

Figura 1 - Necrose epidérmica metabólica. 1A, hiperceratose e fissuras em coxim (cão 1). 1B, hiperceratose paraceratótica, edema de camada superior da epiderme e hiperplasia de estarto basal. (Hematoxilina e eosina, 400x).

revelou anemia normocítica normocrômica e a urinálise demonstrou proteinúria, hematúria, bilirrubinúria e cilindrúria granulosa. O raspado de pele foi negativo para ácaros. A sorologia para leishmaniose por ELISA e imunofluorescência indireta foi não-reagente. A análise bioquímica revelou hipoalbuminemia e hiperglobulinemia, aumento da fosfatase alcalina (FA) e valores normais de alaninoaminotransferase (ALT), bilirrubina, glicose, uréia e creatinina. O exame histopatológico de pele revelou hiperceratose paraceratótica, edema intracelular com palidez da camada superior da epiderme, hiperplasia de estrato basal e moderado infiltrado inflamatório misto na derme superficial (Figura 1B). Com base nesses achados, firmou-se o diagnóstico de NEM. O tratamento instituído foi: amoxicilina com clavulanato de potássio, 
suplemento de ácidos graxos essenciais, sulfato de zinco e suplementação alimentar. Também foram recomendados banhos com clorexidine a $2,5 \%$ a cada quatro dias. A partir do sétimo dia do tratamento, houve melhora do quadro. Após um mês e meio, o proprietário interrompeu o tratamento, ocorrendo piora gradativa. Quatro meses após o início do tratamento, o cão retornou em péssimo estado geral, sendo solicitada a eutanásia. Nesse momento, observou-se neutrofilia, sem desvio à esquerda. À necropsia, o fígado encontrava-se diminuído de volume, firme, exibindo macronodulações por todo parênquima. O exame histopatológico do fígado revelou múltiplas nodulações separadas por septos fibrosos espessos permeados por ductos biliares proliferados e focos de infiltrado inflamatório crônico, compatível com cirrose hepática.

Caso 2: Cadela sem raça definida, nãocastrada, com oito anos de idade, foi atendida apresentando anorexia, apatia, vômitos e melena. O exame físico revelou emaciação, apatia, desidratação e mucosas pouco coradas a subictéricas. A pelagem estava fosca, dura e quebradiça, com discreta seborréia seca, além de dermatose crostosa e ulcerativa nas comissuras labiais e eritema, alopecia e descamação nas extremidades dos membros torácicos. Não havia prurido ou dor. O hemograma revelou anemia arregenerativa, hipoproteinemia, leucocitose com neutrofilia e desvio à esquerda regenerativo e a urinálise demonstrou baixa densidade e bilirrubinúria. A análise bioquímica revelou hipoalbuminemia e aumento da FA. O raspado de pele e a cultura fúngica foram negativos para ácaros e fungos, respectivamente. O exame histopatológico de pele revelou as mesmas alterações descritas no caso 1 . Foi instituído tratamento suporte com fluidoterapia, bloqueadores de receptores de $\mathrm{H}_{2}$, antieméticos e antibioticoterapia, além de suplementação vitamínica e vermifugação. Houve piora do quadro com morte ao final da terceira semana. À necropsia, o fígado encontrava-se com coloração bronze e firme. Havia icterícia generalizada. O exame histopatológico do fígado revelou edema intersticial, focos de necrose centrolobular, vacuolização hepatocelular e várias inclusões basofílicas de localização intranuclear, características da hepatite infecciosa canina.

Caso 3: Cão macho, Husky Siberiano, de três anos e seis meses de idade, com queixa de lesões no escroto, hiporexia e polidipsia. O exame físico revelou dermatite crostosa e ulcerativa em escroto, hiperceratose de coxins palmares e lesões eritematosas e crostosas em extremidades distais de membros torácicos e ascite. O hemograma revelou anemia microcítica hipocrômica, leucocitose por neutrofilia e hipoproteinemia. A urinálise demonstrou proteinúria. A bioquímica sérica revelou hipocolesterolemia, hipoalbuminemia, hipoglobulinemia e aumento de FA. O derrame peritoneal era transudato puro. Os achados histopatológicos foram semelhantes aos do caso1. O tratamento baseou-se no controle dietético, antibioticoterapia e diurético. A laparotomia exploratória revelou fígado diminuído de volume com nodulações distribuídas por todo o parênquima. O exame histopatológico demonstrou cirrose. Quatro meses após a consulta inicial o cão foi submetido à eutanásia devido à piora do quadro.

A NEM é uma condição endócrinometabólica rara, que acomete humanos e cães, havendo também relatos em gatos (BYRNE, 1999; PATEL et al., 1996; SCOTT et al., 2001). As lesões dermatológicas encontradas nos animais do presente estudo estavam de acordo com as descritas na literatura (GROSS et al., 2005; MILLER et al., 1990; OUTERBRIDGE, 2005; WALTON et al., 1986). Alguns autores afirmaram que a lesão dermatológica mais freqüente é a hiperceratose dos coxins, com ocorrência variando de $91 \%$ a $94 \%$ (BYRNE, 1999; OUTERBRIDGE, 2005). Esta alteração foi verificada nos casos 1 e 3 do presente estudo. Apatia, polidipsia e dificuldade para caminhar são descritas na literatura e foram verificadas no caso 1 . Nos casos 2 e 3, as alterações clínico-laboratoriais sugeriam doença hepática (BYRNE, 1999; SCOTT et al., 2001; WALTON et al., 1986). A etiopatogenia das lesões de pele em cães com NEM e humanos com ENM não é bem conhecida. Em humanos, o ENM é um marcador cutâneo da produção de glucagon por células tumorais das ilhotas pancreáticas. Em cães, a maioria dos casos relaciona-se à enfermidade hepática (BYRNE, 1999; MILLER et al., 1990; MILLER et al., 1991; SCOTT et al., 2001). A etiologia da hepatopatia na maioria das vezes é desconhecida, podendo estar associada à micotoxicose e a drogas anticonvulsivantes (BYRNE, 1999; LITTLE et al., 1991; OUTERBRIDGE, 2005). A causa específica da degeneração epidérmica pode ocorrer por desequilíbrio nutricional, sendo sugeridos hipoaminoacidemia, deficiência de biotina, ácidos graxos essenciais ou zinco, resultantes de anormalidades metabólicas causadas por hiperglucagonemia e/ou disfunção hepática (SCOTT et al., 2001). A hiperglucagonemia, quando presente, poderia explicar o risco de desenvolvimento de diabete melito e hipoaminoacidemia vistos em alguns animais e humanos com a doença (BYRNE, 1999; MILLER et al., 1990; OUTERBRIDGE, 2005). Também tem sido sugerido que o glucagon aumenta a quantidade de ácido araquidônico e seus metabólitos na epiderme, o 
que poderia contribuir para as alterações inflamatórias da pele, sobretudo nos pontos de apoio (KASPER \& McMURRY, 1991; PATEL et al., 1996; SCOTT et al., 2001). Acredita-se que o metabolismo anormal de zinco e ácidos graxos também possa ser responsável pelo desenvolvimento da NEM (BYRNE, 1999). Os diagnósticos diferenciais incluíram o lupus eritematoso sistêmico, pênfigo foliáceo, dermatose responsiva ao zinco e dermatose do alimento genérico. Outros diferenciais, como demodiciose, dermatofitose, necrólise epidérmica tóxica, vasculite, linfoma cutâneo, erupção por droga, eritema multiforme crônico, foliculite bacteriana e dermatite de contato foram excluídos a partir do histórico, exame físico e laboratorial e achados histopatológicos (BYRNE, 1999; GROSS et al., 2005; WALTON et al., 1986; MILLER et al., 1990). O diagnóstico definitivo da doença baseia-se no exame dermatopatológico que, nos três casos descritos, revelou paraceratose, edema intra e intercelular com palidez da camada superior da epiderme e hiperplasia do estrato basal, compatíveis com as alterações previamente descritas (BYRNE, 1999; GROSS et al., 2005; OUTERBRIDGE, 2005; SCOTT et al., 2001). Parte do tratamento referido por vários autores baseia-se na administração intravenosa de aminoácidos, com a resolução das lesões de pele e diminuição da dor (BYRNE, 1999; OUTERBRIDGE, 2005). O fato de que alguns cães respondem melhor à terapia de infusão intravenosa de aminoácidos do que à suplementação protéica oral suporta a hipótese proposta para o aumento do catabolismo de aminoácidos na NEM. A via de administração intravenosa desvia-se, inicialmente, da circulação portal, resultando em maior distribuição de aminoácidos para os tecidos periféricos antes de chegar ao fígado, onde o catabolismo pode ocorrer (OUTERBRIDGE, 2005; OUTERBRIDGE et al., 2002). A superalimentação oral introduzida no caso 1 resultou em melhora significativa do quadro dermatológico e sistêmico a partir do sétimo dia do início do tratamento. Nos casos 2 e 3, a terapia foi instituída visando, sobretudo, controlar as complicações de doença hepática. Deve-se ter em mente que a suplementação protéica em animais com comprometimento hepático ou renal pode desencadear um quadro de encefalopatia hepática (OUTERBRIDGE, 2005).

Nos três animais do presente relato, havia doença hepática concorrente, fato descrito na maioria dos casos de NEM em cães (BYRNE, 1999; GROSS et al., 2005; MILLER et al., 1990). As alterações histopatológicas do fígado nos dois casos foram características de cirrose (MILLER et al., 1990; TURNWALD et al., 1989). O exame histopatológico de fígado do caso 2 revelou inclusões intranucleares características da hepatite infecciosa canina, achado ainda não descrito na literatura. O prognóstico da doença é desfavorável, a menos que se detecte e remova, quando presente, um tumor pancreático produtor de glucagon ou a causa primária da hepatopatia, assumindo que o dano morfofuncional seja reversível. A maioria dos cães morre ou é eutanasiada dentro de cinco meses após o desenvolvimento das lesões cutâneas (BYRNE, 1999; LITTLE et al., 1991; OUTERBRIDGE, 2005; SCOTT et al., 2001). Entretanto, há relatos de animais mantidos por um ano ou mais com a superalimentação oral e infusões periódicas de aminoácidos via parenteral (OUTERBRIDGE, 2005; OUTERBRIDGE et al., 2002). Os animais dos casos 1 e 3 foram submetidos à eutanásia quatro meses após o diagnóstico e a cadela do caso 2 morreu após três semanas de internação. Concluindo, a NEM é um marcador cutâneo reacional de séria doença sistêmica, cujo diagnóstico definitivo é obtido por meio da dermatopatologia. Apesar do prognóstico desfavorável, o diagnóstico e o tratamento precoces podem prover ao animal maior sobrevida com qualidade.

\section{REFERÊNCIAS}

BYRNE, K.P. Metabolic epidermal necrosis-hepatocutaneous syndrome. Veterinary clinics of North America: Small Animal Practice, v.29, n.6, p.1337-1355, 1999.

GROSS, T.L. et al. Skin diseases of the dog and cat clinical and histopathologic diagnosis. 2.ed. Oxford: Blackwell Science, 2005. 932p.

KASPER, C.S.; McMURRY, K. Necrolytic migratory erythema without glucagonoma versus canine superficial necrolytic dermatitis: Is hepatic impairment a clue to pathogenesis? Journal of the American Academy of Dermatology, v.25, n.3, p.534-541, 1991.

LITTLE, C.J.L. et al. Hepatopathy and dermatitis in a dog associated with the ingestion of mycotoxins. Journal of Small Animal Practice, v.32, p.23-26, 1991.

MILLER, W.H. Jr. et al. Case report: necrolytic migratory erythema in a dog with a glucagons-secreting endocrine tumor. Veterinary Dermatology, v.2, p.179-182, 1991.

MILLER, W.H. Jr. et al. Necrolytic migratory erythema in dogs: a hepatocutaneous syndrome. Journal of the American Animal Hospital Association, v.26, p.573-581, 1990.

OUTERBRIDGE, C.A. Hepatocutaneous syndrome. In: ETTINGER, S.J.; FELDMAN, E.C. Textbook of veterinary internal medicine. 6.ed. St Louis: Elsevier Saunders, 2005. V.1, cap.19, p.72-75.

OUTERBRIDGE, C.A. et al. Plasma amino acid concentrations in 36 dogs with histologically confirmed superficial necrolytic dermatitis. Veterinary Dermatology, v.13, p.177-186, 2002. 
PATEL, A. et al. Case report: a case of metabolic epidermal necrosis in a cat. Veterinary Dermatology, v.7, p.221-226, 1996.

PUJOL, R.M. et al. Necrolytic migratory erythema: clinicopathologic study of 13 cases. International Journal of Dermatology, v.43, p.12-18, 2004.

SCOTT, D.W. et al. Small animal dermatology. 6.ed. Philadelphia: Saunders, 2001. 1528p.
TURNWALD, G.H. et al. Failure to document hyperglucagonemia in a dog with diabetic dermatopathy resembling necrolytic migratory erythema. Journal of the American Animal Hospital Association, v.25, p.363-369, 1989.

WALTON, D.K. et al. Ulcerative dermatosis associated with diabetes mellitus in the dog: a report of four cases. Journal of the American Animal Hospital Association, v.22, p.7988, 1986. 